P. M. Benoit had four exhibits of hybrids. Festuca rubra $\times$ Vulpia myuros was claimed as new to science. A single plant was found in Merioneth, morphologically intermediate, and completely sterile. Cardamine flexuosa $\times$ hirsuta he had synthesized, making successful crosses in both directions. Myosotis caespitosa $\times$ scorpoides he found in a marshy meadow at Dolgelley in 1956--this is new to the British Isles. He also had a very convincing exhibit of the common hybrid Senecio aquaticus $\times$ jacobaea, which is partially fertile and very variable and forms complex hybrid swarms. Dr. S. M. Walters and Miss A. Martin (Cambridge) showed an interesting study of Calystegia sepium and $C$. sylvestris. This was based on five populations in and near Cambridge for which they had scored measurements of parts of the flowers and arranged them on the principle of Anderson's "Hybrid Index". Both species are markedly incompatible, and small populations usually arise from a single clone and therefore set little or no seed, but seed is set in larger populations or those which are heterogeneous. Their analysis showed that morphologically intermediate populations of presumed hybrid origin occur frequently in the vicinity of Cambridge and presumably arose by cross-fertilization.

Two exhibits directed attention to new techniques. B. E. Juniper (Oxford) showed replicas of leaf surfaces obtained by the use of the electron microscope. These included, for example, Oxalis corniculata var. atropurpurea under a magnification of 34,000 linear. When the investigation of structures beyond the resolution of the light microscope is more advanced, new characters may be revealed to assist the work of taxonomists. D. E. Bradley exhibited a series of flowers of native orchids preserved by an embedding technique. After treatment in a colour-preserving solution, they were dried and embedded in transparent blocks of cold-setting 'Ceemar' resin.

Other aspects of British botany were represented by further exhibits, but it was clear that the Distribution Maps Scheme, the relationship to the European flora, and hybrids were the main interests of members of the Society in 1957. Progress made during the year as demonstrated by the exhibits represents a sound contribution to knowledge.

J. E. LousLixy

1 Jurges, N. A., and Heywood, v. H., Nature, 179, 696 (1957).

\title{
THE GEOGRAPHICAL ASSOCIATION
}

T THE annual conference of the Geographical Association was held at the London School of Economics during December 31-January 3. Prof. P. W. Bryan, in his presidential address, fascinated and impressed a very large audience by a series of beautiful coloured photographs and his insistence that geographers must deal primarily with the land. scape as a whole, including the interrelated parts of the physical and the cultural. With the whole landscape as their basis, research workers could then go on to a detailed consideration of particular features.

One of these particular features, the landscape of glacial erosion, received detailed treatment by $\mathbf{M r}$. Vaughan Lewis, of Cambridge, in an analysis of the recent work done on "Erosion by Cirque and Valley Glaciers". He felt that the most helpful assumption now is that frost shatter is most severe in bergschrunds and related features, such as the enclosed head-wall gap reached by the upper tunnel dug through Vesl-Skautbreen, Jotunheimen, in 1951, when melt-water falls on to rock that is still a degree or so below the freezing point. This occurs in spring or early summer in the few weeks before the temperatures in the rock, and ice in the neighbourhood of the bergschrund, are raised to the freezing point.

$\mathrm{He}$ also considered that if rotation occurs as a result of the great downward thrust of an icefall, bed abrasion may be inereased locally, partly by this great downward pressure and probably more effectively by the higher velocity induced in the deeper lower layers of ice in contact with the bed. Ice has not sufficient strength to hold very small stones firmly enough to do much grinding and gouging of the much stronger rock, but if the boulders or blocks of rock are large, the ice can drag them past the rock with great force and produce correspondingly great erosion. If the rock is well jointed, this abrasion, coupled with frost shatter wherever low temperatures can reach the rock, may account for the bulk of glacial erosion. But if the rocks are massive and like granites and certain metamorphic rocks consolidated under great pressure, then joints may form near the surface-the primary ones lying parallel to the surface-as a result of the release of pressure on the removal of the overlying rocks. The rocks may burst upwards, as it were, an action which has been noted in certain New England quarries. This action may help the recession of the walls bounding valley glaciers. It is hoped that Mr. Lewis's findings may be published in full at 'a later date.

One aspect of the cultural landscape, namely, urban geography, received detailed treatment in several lectures and constituted the main theme of the conference. Prof. A. E. Smailes, of Queen Mary College, London, read a paper on "Urban Studies" and paid tribute to the pioneer work that had been done on spheres of urban influence and in many detailed studies of urban morphology. The latter, largely based on maps, had greatly added to our knowledge of towns, but sometimes the use of a two-dimensional map failed to convey the true character of an urban area. It could easily ignore what Prof. Smailes called 'the texture' of a town by failing to emphasize the three-dimensional aspect of buildings. With a wealth of illustrative matter and descriptive detail, he gave examples of various types of towns viewed in three dimensions and went on to an analysis of the main forms of urban growth in the past century. He distinguished, for example, with the aid of air photographs, the terrace ribbing pattern of much Victorian housing, the villa studding of more recent housing, and finally the block clumping of flats in modern times.

Prof. E. W. Gilbert, of Oxford, in a lecture on "English Seaside 'Towns", stated that roughly 2 t million people now lived permanently in these places. After describing their diverse origins and present functions, he discussed the many lines of research on them now proceeding in several universities. He made a special plea for more work on the medical 
geography of resorts, emphasizing that little was known of the precise meaning of the 'bracing' and 'relaxing' qualities of places and of their exact influence on the human body. He felt strongly that more attention should be given to descriptive geography and especially to the aspect of towns. He urged geographers to analyse the beauty of urban and rural scenery and not to be afraid of expressing their own subjective feelings. Educated geographical opinion should unite to preserve the besuty of both coast and seaside Regency buildings.

Mrs. D. Monteith gave a fascinating account of the development of Saffron Walden, showing how the main-line railway had avoided the town and had greatly impeded its subsequent growth. Later in the week, Mrs. Monteith took a party of members to Saffron Walden to explain in more detail the methods and results of her survey. Dr. A. Garnett gave a detailed study of atmospheric pollution as a factor of urban geography, and Mr. G. F. A. Wilmot introduced a different facet by considering the scope of railway geography in urban areas and illustrating it by a coach tour to examine some aspects of railway development in North London. Prof. Beaver introduced yet another aspect by analysing the changing industrial landscape of Great Britain, emphasizing the great part that modern technology is playing in modifying the effects of industrialization.

The teaching side of geography also received suitable attention. A very lively discussion on the effect of Ordinary Level examinations on the teaching of geography opened the conference, and on the last day of the lectures Miss P. M. Jeffery gave a lesson showing the follow-up of a field expedition in an urban area, and Mrs. I. L. M. Long presented the results of the research project into "The Interpretation of Geographical Pictures by Secondary School Children".

The last day of the conference was devoted to a series of excursions which included, in addition to the two already mentioned, a tour of the sites of London's former airports, a tour of metropolitan Essex, a traverse by coach to Cambridge, and a walking expedition to examine the site and function of the City of London.
R. C. HONEYBONE

\section{THE NATIONAL PHYSICAL LABORATORY}

\section{REPORT FOR 1956}

$\mathrm{T}$ HE annual report* for 1956 of the National Physical Laboratory, Teddington, gives an excellent survey of the fundamental and applied research carried out during the year in the nine Divisions and Test House of the Laboratory. It contains also the report of the Executive Committee which was presented to the General Board at its meeting on May 23, 1957, the annual open day of the Laboratory (see Nature, 180,166 ; 1957).

The Executive met seven times during the year, but refrained from taking any major policy decisions while changes in the directorship of the Laboratory were taking place. Sir Edward Bullard, whose resignation as director became effective on December 31, 1955, was succeoded by Dr. R. L. Smith-Rose, who continued as acting-director until September 14, 1956, when Dr. G. B. B. M. Sutherland assumed his appointment as director. The arrangement whereby certain members of the Executive Committee form panels to visit and report on the scientific divisions of the Laboratory was continued, and reports were considered during the year from the panels which visited the Mathematics, Metallurgy and Physics Divisions. Both the chairman of the mathematics panel and the superintendent of the Mathematics Division made representations to the Committee that the supply of trained numerical analysts was inadequate to meet the incressing use of high-speed computers and that staff was not available in the universities to provide for the teaching of numerical analysis on an adequate scale. A panel, with Sir Charles Darwin as chairman, was therefore set up by the Committee, to consider this matter and to advise on whether special facilities for the training of numerical analysts should be provided at the Laboratory, in addition to using other means elsewhere.

- Department of Scientiflc and Industrial Research. Report of the National Physical Laboratory for 1956. Pp. vili $+104+5$ plates. (London: H.M. Stationery Ofle, 1957.) 58. net.
Two new buildings, one for radiological work and the other for low-temperature research, were completed during 1956 and occupied by the Physics Division. The 24 in. $\times 20$ in. high-speed wind tunnel in the Aerodynamics Division was put into operation and the construction begun of a new workshop on the West Aero site and of a new road and entrance to the Laboratory from Hampton Road. Good progress has been maintained on the new Ship Hydrodynamics Laboratory at Feltham and the completion date for the whole project is forecast in the report as early 1959. With regard to future building requirements of the Laboratory, it is still required that priority be given to the provision of a new library, lecture hall and canteen, and accommodation for an expanded Control Mechanisms and Electronics Division.

Four new booklets, Nos. 13, 14, 15 and 17, in the series "Notes on Applied Science" were published during the year, in addition to the proceedings of the symposia on "Boundary Layer Effects", "Cavitation in Hydrodynamics" and "Creep and Fracture of Metals at High Temperatures". In the series "Units and Standards of Measurement employed at the N.P.L." a new edition of Part 1 (on length, mass, time-interval, etc.) and a revised edition of Part 2 (on light) were issued. Three books, "Mass Spectro. meter Researches", "Tables of Weber Parabolic Cylinder Functions" and "Wage Accounting by Electronic Computer" were published, of which the last mentioned has been so well received that it has already been reprinted three times. This work consists of the first report of the Interdepartmentel Study Group on the Application of Computer Techniques to Clerical Work. Several earlier publications have also been reprinted including, in particular, the proceedings of the 1953 symposia on "Engineering Dimensional Metrology" and on "Automatic Digital Computation". 